\title{
Possibilidades e tensões no trabalho com as práticas corporais no cuidado em saúde mental: reflexões construídas em um caps ii na cidade de serra/es
}

\section{Possibilities and tensions at work with corporate practices in mental health care: reflections constructed in a caps ii in the city of serra / es}

\section{Posibilidades y tensiones en el trabajo con prácticas corporales en el cuidado de salud mental: reflexiones construidas en un caps ii en la ciudad de serra/es}

\author{
(iD) Gabriela Linhares Daltio \\ Secretaria Municipal de Saúde da Prefeitura Municipal da Serra, Serra, Espírito Santo, \\ Brasil \\ gabrieladaltio@hotmail.com \\ iD Leonardo Trápaga Abib \\ Universidade Federal do Espírito Santo, Vitória, Espírito Santo, Brasil \\ leoabib@gmail.com \\ iD 9 \\ Ivan Marcelo Gomes \\ Universidade Federal do Espírito Santo, Vitória, Espírito Santo, Brasil \\ ivanmgomes@hotmail.comv
}

Resumo: O objetivo deste artigo é analisar como foram organizadas e constituídas as práticas corporais no cuidado de usuários de um Caps do município da Serra/ES, tendo como base os conceitos de autonomia e empoderamento presentes nas Políticas de Promoção da Saúde e de Saúde Mental. Valemo-nos das pistas do método da cartografia para acompanhar a rotina desse Caps. A partir das análises desse cotidiano, registradas em diários de campo, abordamos uma categoria que foi construída e intitulada "Práticas corporais no Caps Mestre Álvaro?". Com 
tal categoria interpretamos os encontros que a Educação Física proporcionou aos usuários com a oferta de práticas corporais e sua efetivação no mundo do trabalho e no espaço de tratamento desses indivíduos que aconteceram em meio a tensões e disputas.

Palavras-chave: Educação Física. Saúde Mental. Autonomia. Empoderamento.

Abstract: The objective of this article is to analyze how corporal practices were organized and constituted in the care of users of Caps Mestre Álvaro of the Municipality of Serra / ES, based on the concepts of autonomy and empowerment present in Health Promotion and Mental Health Policies. For this research we used clues of the method of cartography to follow the routine of Caps. From the analysis of this daily we made a category called "Corporal Practices at the Caps Mestre Álvaro?". From this category we interpret the relation about Physics Education and corporal practices for the users and the effectiveness in the world of work and in the space to the tratamento for this individuals happened in between tensions and disputes.

Keywords: Physical Education. Mental Health. Autonomy. Empowerment.

Resumen: El objetivo de este artículo es analizar cómo fueron organizadas y constituidas las practicas corporales en el cuidado de usuarios de un caps de la municipalidad de Serra/ES, teniendo como base los conceptos de autonomía y empoderamiento presentes en las Políticas de Promoción de Salud y de Salud Mental. Nos valemos de las pistas del método cartográfico para acompañar la rutina de este caps. A partir de los análisis de este cotidiano, registrados en diarios de campo, abordaremos una categoría construida llamada "Practicas corporales en el Caps Mestre Alvaro?". Con tal ejecución en el mundo del trabajo y en el espacio de tratamiento de estos individuos que sucedieron en medio de tensiones y disputas.

Palabras clave: Educación Física. Salud Mental. Autonomía. Empoderamiento.

Submetido em: 16/01/2019

Aceito em: 06/03/2020 
Possibilidades e tensões no trabalho com as práticas corporais no cuidado em saúde... Gabriela Linhares Daltio • Leonardo Trápaga Abib • Ivan Marcelo Gomes

\section{Apresentação da temática}

A Reforma Psiquiátrica brasileira promulgada nos anos 2000 é fruto de um processo intenso de reivindicações do movimento da luta antimanicomial, movimento social que emerge no Brasil durante a década de 1970 pautando a garantia de um tratamento humanizado para pessoas em intenso sofrimento psíquico. Desde criada, a lei da reforma psiquiátrica vem gerando mudanças no cuidado e no olhar para com esses indivíduos, ampliando cada vez mais o acesso público e comunitário através da criação de novos serviços de base territorial e aberta, de modo a substituir uma rede que era prioritariamente manicomial.

A partir da implementação de modelos substitutivos ao hospital psiquiátrico, novas modalidades terapêuticas ganharam força. Atualmente, são projetos cujo objetivo é fortalecer o acesso à saúde, a cidadania e a inclusão social dos usuários. Segundo Alvarenga e Dimenstein (2006, p. 306), "estas questões confirmam ser a reforma psiquiátrica a construção de um novo lugar sociopolítico-conceitual-cultural para a loucura, de novas formas de lidar com a diferença".

Ao se priorizar o modelo de desinstitucionalização, ou seja, mudar o foco do atendimento de instituições hospitalares e fechadas para instituições abertas e comunitárias, aposta-se no encontro da loucura com a sociedade, e, a partir daí, na oportunidade de se potencializar relações sociais e de vida. O cuidado no território de vida do sujeito, em ambientes substitutivos, vem promovendo, entre outras atividades, oficinas terapêuticas para pensar e ampliar o cuidado dos indivíduos em sofrimento psíquico, buscando um meio a mais para se abrir ao mundo vivo da cidade, se ocupando, assim, com a produção de vida dessas pessoas (FERREIRA et al., 2017).

Nesse sentido, em contraposição ao modelo manicomial, é preciso fortalecer "[...] sobretudo, a construção efetiva de redes de cuidado entre os serviços e entre diferentes equipamentos sociais, 
Possibilidades e tensões no trabalho com as práticas corporais no cuidado em saúde... Gabriela Linhares Daltio • Leonardo Trápaga Abib • Ivan Marcelo Gomes

envolvendo a cidade com suas diferentes e potentes estratégias de cuidado" (AMORIM; DIMENSTEIN, 2009, p. 202). Em um contexto de tratamento extramanicômico, o cuidado em saúde mental passa a ser provido entre sujeito, família, comunidade e os profissionais dos serviços de saúde.

Ferreira et al. (2017) e Alvarenga e Dimenstein (2006) destacam os desafios impostos ao processo da reforma psiquiátrica e aos atravessamentos vivenciados nessa lida. Considera-se essa reforma um processo ainda inacabado na luta antimanicomial; de fato, ainda se encaram, de forma latente, ações manicomiais no dia a dia da Rede de Atenção Psicossocial (Raps), fato que gera angústia ao se pensar em como produzir autonomia num ambiente em que ainda se enfrenta certa confusão na relação entre cuidado versus tutela (DALTIO, 2018). No entanto, Garcia (2011) alerta que não existe necessariamente a garantia da oferta desses serviços, mesmo que sejam da ordem da demanda de políticas nacionais da humanização do cuidado.

A política de saúde mental (Lei $n^{\circ}$ 10.216) firma, em seu parágrafo único, nos itens VIII e IX, os direitos das pessoas portadoras de transtorno mental de serem tratadas por meios menos invasivos possíveis, em ambiente terapêutico, preferencialmente em sua comunidade. Em seu artigo $4^{\circ}$, parágrafo primeiro, aponta que "o tratamento visará, como finalidade permanente, à reinserção social do paciente em seu meio" (BRASIL, 2001). O parágrafo segundo, ao discorrer sobre um regime de tratamento em internação, dispõe que se deverá oferecer "assistência integral à pessoa portadora de transtornos mentais, incluindo serviços médicos, de assistência social, psicológicos, ocupacionais, de lazer, e outros" (BRASIL, 2001). A educação física pode intervir visando a contribuir com as prerrogativas expostas acima, principalmente quando se leva em consideração uma abordagem conectada às diretrizes de trabalho como a desinstitucionalização e a humanização.

A Política Nacional de Promoção da Saúde (BRASIL, 2014) e a Política Nacional de Saúde Mental (BRASIL, 2001) contemplam, em seus textos, o direcionamento do cuidado baseado numa perspec- 
Possibilidades e tensões no trabalho com as práticas corporais no cuidado em saúde... Gabriela Linhares Daltio • Leonardo Trápaga Abib • Ivan Marcelo Gomes

tiva ampliada de saúde. Esse novo olhar insere nas discussões da reforma psiquiátrica conceitos como autonomia, que "[...] se refere à identificação de potencialidades e ao desenvolvimento de capacidades possibilitando escolhas conscientes de sujeitos e comunidades sobre suas ações e trajetórias" (BRASIL, 2014, p. 27) e empoderamento, que se refere "ao processo de intervenção que estimula os sujeitos e coletivos a adquirirem o controle das decisões e das escolhas de modos de vida adequado às suas condições sócio-econômico-culturais" (BRASIL, 2014, p. 27). Consideramos esses conceitos importantes para se debater estratégias de cuidado e gestão no campo da saúde mental, enquanto balizadoras para o trabalho da educação física nos serviços que constituem a Raps.

Para que estas novas propostas pudessem ser efetivadas, foi instituída uma série de serviços substitutivos ao modelo manicomial, dentre eles o Centro de Atenção Psicossocial (Caps), ${ }^{1}$ considerado um dos principais dispositivos constituintes da rede pública de saúde. Assim, diferente do modelo centrado na clausura e privação de liberdade, novas formas de cuidado obtiveram força para serem experimentadas, oportunizadas também pela presença de outros profissionais no atendimento, tais como os profissionais da educação física.

Nos Caps, profissionais de diversas áreas, inclusive da educação física, representam a oportunidade de um novo atendimento através de oficinas terapêuticas, que possibilitam a seus usuários um lugar em que podem falar, expressar-se e serem acolhidos (MIRANDA; AZEVEDO, 2011). As oficinas terapêuticas, hodiernamente elemento organizador do cotidiano dos serviços de saúde mental, são consideradas importantes espaços para a educação física como dispositivo de intervenção ao tratamento de pessoas com intenso sofrimento psíquico.

Em consonância com um modelo que valoriza as relações sociais e que compreende que a saúde também está atrelada a di-

\footnotetext{
1 A Lei da Reforma Psiquiátrica prevê os seguintes tipos de Centros de Atenção Psicossociais: para o atendimento de população adulta existem os Caps I (para municípios de pelo menos 15 mil habitantes), Caps II (para municípios com mais de 70 mil habitantes), Caps III (municípios a partir de 150 mil habitantes) e Caps AD (álcool e outras drogas). Para o atendimento da infância e adolescência existe o Capsi. Desses, somente o Caps III tem atendimento 24 horas por dia e com vagas para internação breve.
} 
Possibilidades e tensões no trabalho com as práticas corporais no cuidado em saúde... Gabriela Linhares Daltio • Leonardo Trápaga Abib • Ivan Marcelo Gomes

mensões socioeconômicas e culturais, alguns professores de educação física propõem, em suas oficinas terapêuticas, atividades de práticas corporais, ${ }^{2}$ um conceito diferenciado que desvincula a discussão e a intervenção centrada na atividade física (DALTIO, 2018). Tal conceito considera a manifestação da cultura corporal dança, luta, jogo, esporte, dentre outros - como eixo principal da educação física (SOARES et al., 1992).

Com a recente e incipiente entrada da educação física nos Centros de Atenção Psicossocial, ${ }^{3}$ sentiu-se uma maior necessidade em realizar estudos e pesquisas sobre a atuação dos professores nos serviços de atenção à saúde mental (FERREIRA, 2013; FURTADO et al., 2015; LEONIDIO et al., 2014; WACHS, 2008; 2016). Uma melhor compreensão e entendimento das práticas corporais como parte efetiva do tratamento e cuidado em saúde mental é de extrema importância, já que é pouca a gama de estudos sobre o assunto, aliada à crescente participação de tais profissionais nesse campo da saúde coletiva (SANTOS et al., 2014).

Para Wachs (2016, p. 48), a "saúde mental é um campo que melhor acolhe a Educação Física e suas possibilidades de intervenção". Diante das orientações e delineamentos apresentados nas políticas de saúde mental discutidas nesse tópico, é coerente afirmar que o desenvolvimento das atividades da área da educação física apresenta a potencialidade de realizar ações nesse âmbito devido às demandas apresentadas nesses documentos e às características de ação dos profissionais dessa área (DALTIO, 2018).

No município da Serra/ES, localizado na região metropolitana de Vitória, existem três Caps, sendo dois voltados para o atendimento de pessoas adultas e um para a infância e adolescência. Nesses equipamentos da rede de atenção psicossocial atuam professores de educação física ministrando e coordenando oficinas, grupos e atendimentos individuais. Uma das autoras do presente

\footnotetext{
2 A partir dos ideais da Política Nacional de Promoção da Saúde (PNPS, 2014), consideramos práticas corporais como atividades que dão sentido ao praticante, pois, nessa perspectiva, podem ser um espaço de convívio e sociabilidade e de promoção da recuperação familiar e social.

3 A partir da portaria n. 336/GM, de 19 de fevereiro de 2002, o professor de educação física passa a compor o quadro de profissionais que podem fazer parte das equipes dos Caps.
} 
Possibilidades e tensões no trabalho com as práticas corporais no cuidado em saúde... Gabriela Linhares Daltio • Leonardo Trápaga Abib • Ivan Marcelo Gomes

texto atuou durante quatro anos em um dos serviços desse município, chamado Caps II Mestre Álvaro.

Dito isso, o objetivo da presente pesquisa foi analisar como foram organizadas e constituídas as práticas corporais no cuidado dos usuários do Caps II Mestre Álvaro, tendo como base para discussão os conceitos de autonomia e empoderamento, que estão presentes nas políticas de saúde e de saúde mental.

O texto está estruturado da seguinte forma: em um primeiro momento, apresentaremos os conceitos de autonomia e empoderamento na interface com a saúde mental; depois, as orientações metodológicas da pesquisa realizada; na sequência, apresentaremos uma análise em torno da oferta de práticas corporais no Caps em questão e, por fim, as considerações finais.

\section{Conceitos de autonomia e empoderamento na saúde mental}

A orientação do trabalho em saúde mental é regida pelos conceitos de autonomia e empoderamento, que se apoiam em leis e portarias do serviço de saúde pública no Brasil (HIRDES, 2009; ALVES et al., 2013). Um dos maiores objetivos da reforma psiquiátrica é a retomada da cidadania dos que são considerados loucos e incapazes. Ações que se propõem a esse objetivo são de extrema importância para garantir um cuidado mais humanizado a essas pessoas. No campo da saúde mental, Jorge et al. (2011, p. 3.058) complementam: "a autonomia como dispositivo do cuidado integral é o resgate da cidadania dessas pessoas, buscando a autoestima, o poder contratual e o autocuidado, tendo como pilar o projeto de vida de cada usuário do CAPS".

Nesta direção, esse conceito seria, assim, uma ferramenta importante no cuidado em saúde mental, algo que requer mais que fórmulas prontas. Essa abordagem não está direcionada, a priori, a uma construção de autonomia padrão que poderia servir em 
Possibilidades e tensões no trabalho com as práticas corporais no cuidado em saúde... Gabriela Linhares Daltio • Leonardo Trápaga Abib • Ivan Marcelo Gomes

qualquer situação, mas apoiada numa construção constante de modos de cuidado que buscam adequar-se a cada situação. O que determina a autonomia são a coparticipação e a corresponsabilidade das partes envolvidas. Ao se pensar em privilegiar ações que congreguem a busca da autonomia desses indivíduos, trabalha-se também para que outro conceito possa ser vivenciado e oportunizado, o de empoderamento.

Para Alves et al. (2013, p. 52), o empoderamento está diretamente relacionado a ações que promovam "[...] desenvolvimento de potencialidades, aumento de informação e percepção, com o objetivo de que exista uma participação real e simbólica que possibilite a democracia". Para os mesmos autores, o processo de reinserção social das pessoas com transtorno mental, quando perpassado pelo conceito de empoderamento, pode aumentar as possibilidades de cuidado e de socialização do indivíduo. Almeida et al. (2010) destacam que tal conceito significa enxergar os sujeitos como coprodutores de políticas, razão porque não pode ser considerado mera transferência de responsabilidades. Kleba e Wendausen (2009) detalham mais a função do empoderamento:

\begin{abstract}
Empoderamento pessoal possibilita a emancipação dos indivíduos, com aumento da autonomia e da liberdade. O nível grupal desencadeia respeito recíproco e apoio mútuo entre os membros do grupo, promovendo o sentimento de pertencimento, práticas solidárias e de reciprocidade. O empoderamento estrutural favorece e viabiliza o engajamento, a corresponsabilização e a participação social na perspectiva da cidadania. (KLEBA; WENDAUSEN, 2009, p. 733).
\end{abstract}

Carvalho (2004, p. 1.093) traz a noção de empoderamento comunitário que compreende "[...] processos que procuram promover a participação, visando ao aumento do controle sobre a vida por parte de indivíduos e comunidades, à eficácia política, a uma maior justiça social e à melhoria da qualidade de vida". Essa noção tende a superar a questão de que as pessoas socialmente 
Possibilidades e tensões no trabalho com as práticas corporais no cuidado em saúde... Gabriela Linhares Daltio • Leonardo Trápaga Abib • Ivan Marcelo Gomes

marginalizadas devam ser tratadas como dependentes e que devam ser ajudadas, socializadas e treinadas. Já Barreto e De Paula (2014) destacam que, em uma perspectiva emancipatória de empoderamento, requer-se um olhar coletivo para a resolução dos problemas.

As perspectivas apresentadas assemelham-se, visto o fomento e a potencialização do coletivo, no intuito de envolver o sujeito nas questões relativas à saúde. Este posicionamento indica, assim, que aos indivíduos não caberiam apenas a decisão de livre escoIha, mas um sentimento de coparticipação e cooperação para o desenvolvimento de tais questões.

Os conceitos de empoderamento e de autonomia da maneira como constam das políticas de saúde e saúde mental, apesar de complexos e polissêmicos, contêm premissas importantes para o cuidado preconizado na reforma psiquiátrica: pode-se ponderar quão importante seja verificar e analisar como e se a educação física tem possibilitado a promoção de empoderamento/autonomia dos usuários de um Caps II (DALTIO, 2018). Assim, os conceitos apresentados acima orientarão as discussões do presente estudo.

\section{Orientação metodológica}

Com o intuito de conhecer e entender melhor a inserção no cotidiano e as implicações das práticas corporais no campo da saúde mental foram utilizadas algumas pistas do método cartográfico de investigação (PASSOS; BARROS; ESCOSSIA, 2012).

Tal método contempla um caminho para acompanhar processos de trabalho em ambientes de imprevisibilidade e constante reinvenção. Neste sentido, pesquisar não tem como objetivo caminhos fechados e exatos. Pelo contrário, como escrevem Passos e Barros (2012), é o próprio cotidiano que ditará o ritmo e indicará as trilhas para a pesquisa e a intenção é transformar para conhecer. 
Possibilidades e tensões no trabalho com as práticas corporais no cuidado em saúde... Gabriela Linhares Daltio • Leonardo Trápaga Abib • Ivan Marcelo Gomes

Por meio de registros, como diários de campo, procedeu-se à apropriação das informações que caracterizaram o objeto de estudo em análise. Todos os registros aconteceram durante o trabalho de campo de uma das autoras desse texto como professora de educação física do Caps II Mestre Álvaro,4 que relatou o cotidiano das atividades desenvolvidas nesse Caps e é o motivo pelo qual escolhemos esse serviço para investigar e analisar.

Para a realização dos registros, foram determinados elementos como: descrição das atividades; participação dos usuários; participação profissional nas oficinas de práticas corporais; impressões; questões e qualquer tipo de informação considerada necessária, conveniente e que chamasse a atenção para a pesquisa. Para o relato das atividades necessárias à realização da presente pesquisa, substituímos os nomes reais por fictícios no único intuito de preservar a identidade dos participantes.

As atividades acompanhadas durante o processo de pesquisa foram os grupos e oficinas coordenadas pela professora de educação física, além das reuniões semanais da equipe do Caps. Essas atividades eram organizadas de acordo com a demanda do referido serviço, construídas pela equipe multiprofissional em consonância com as possibilidades estruturais do Caps II Mestre Álvaro, e ocorriam semanalmente nos turnos matutino e vespertino, respeitando o horário de funcionamento do serviço (de segunda a sexta de $8 \mathrm{~h}$ às $18 \mathrm{~h}$ ). Um dos exemplos que utilizaremos nas análises foram as oficinas de caminhadas com os usuários do Caps.

Wachs (2008), Machado (2011), Ferreira (2013) e Damico e Bilibio (2015) são autores que recentemente levantaram a discussão a respeito da área da educação física e das práticas corporais no cotidiano do tratamento em saúde mental. Eles apontam algumas questões importantes para o campo acadêmico e profissional, e que, no caso desta pesquisa, podem ajudar a problematizar o dia a dia cartográfico. Pretendemos relacionar essas pistas e problematizações com situações do cotidiano de trabalho para

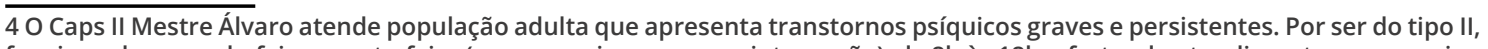
funciona de segunda-feira a sexta-feira (sem possuir vagas para internação), de $8 \mathrm{~h}$ às $18 \mathrm{~h}$, ofertando atendimentos com equipe multiprofissional por meio de consultas, grupos, oficinas e visitas domiciliares. 
Possibilidades e tensões no trabalho com as práticas corporais no cuidado em saúde... Gabriela Linhares Daltio • Leonardo Trápaga Abib • Ivan Marcelo Gomes

que se possa ampliar a discussão sobre a atuação profissional em educação física nos Caps. Devemos enfatizar que essas questões tiveram caráter norteador e não delimitador da problematização apresentada durante o percurso da pesquisa. A partir daí, interpretaremos uma das categorias construídas nesta pesquisa, intitulada "Práticas corporais no Caps Mestre Álvaro?".

Este projeto teve aprovação do Comitê de Ética em Pesquisa com Seres Humanos (CEP) da Universidade Federal do Espírito Santo (UFES), com o parecer $n^{\circ}$. 2.333.715, e da Secretaria Municipal de Saúde do município de Serra (Sesa/Serra-ES), processo $\mathrm{n}^{\circ}$. $58.106 / 2017$.

\section{Práticas corporais no Caps Mestre Álvaro?}

A ideia de cuidado apresentada é atravessada pelo histórico da construção da política de saúde no Brasil, como também pela visão que a sociedade tem do indivíduo com transtorno mental. A desinstitucionalização e os conceitos de autonomia e empoderamento vêm permeando este texto e, de certa forma, direcionando a pesquisa sobre modos de se fazer a educação física. Tais modos serão confrontados com a realidade em que essa área do saber está inserida na saúde mental.

Para tanto, destacamos alguns trechos dos diários de campo produzidos no período em que uma das autoras atuou como professora de educação física do Caps II Mestre Álvaro. Também apresentamos trechos de leis, portarias e manuais que regem o modelo voltado à reforma psiquiátrica, onde são citados modos de se fazer trabalho em saúde mental, particularmente em relação à educação física. Ao revisitar esses diários de campo produzidos a partir da pesquisa de campo, construímos a categoria de análise: "Práticas Corporais no Caps Mestre Álvaro?", em que pretendemos problematizar tais questões para interpretar a atividade da educa- 
Possibilidades e tensões no trabalho com as práticas corporais no cuidado em saúde... Gabriela Linhares Daltio • Leonardo Trápaga Abib • Ivan Marcelo Gomes

ção física na saúde mental, especificamente no Caps Mestre Álvaro entre o período de 2015 a 2018.

Para Wachs (2008), a educação física dentro do Caps têm relações e características que Ihe são próprias. Logo, nas ações da educação física na saúde mental não caberia apenas transpor uma atividade convencional para dentro do espaço dos Caps. É necessário construir práticas corporais que tenham como objetivo maior o cuidado com o usuário. Esse novo olhar, para o autor, deixaria entrar em cena uma educação física que se nomeia "do" Caps e não apenas "no" Caps (WACHS, 2008). "Do" Caps remete a algo construído e congruente com as necessidades do serviço, diferente de "no" Caps, que pode denotar simples transposição de uma atividade para outro local. Em acordo com as ideias desse autor, as práticas corporais propostas em nosso campo de trabalho pretendiam ser "do" Caps e não necessariamente "no" Caps (DALTIO, 2018).

A pergunta que intitula esse tópico justamente nos leva a pensar a maneira como foram operacionalizadas tais atividades, levando em consideração que, além dos conceitos adotados para a atuação, outras questões interferiram no funcionamento das atividades.

$\mathrm{Na}$ tentativa de repensar o manejo das atividades para dar conta do objetivo, a aposta se concentrava em estratégias de construção de ações que pudessem provocar oportunidades de autonomia e corresponsabilização. Com esse intuito, foi necessário reelaborar fórmulas predeterminadas. Em relação às atividades ditas específicas da educação física, insistimos na prioridade em saúde mental que "é a de reinserir o usuário do serviço na sociedade, e que o que vale nas ações em oficinas terapêuticas é o cuidado. Isto requer muito mais que problematizar e articular a sociabilidade; requer a produção de vida e a utilização de espaços coletivos" (DALTIO, 2018, p. 94).

Assinalamos ainda que a imprevisibilidade e a condução da atividade sem as amarras de um planejamento eram rotina. 
Possibilidades e tensões no trabalho com as práticas corporais no cuidado em saúde... Gabriela Linhares Daltio • Leonardo Trápaga Abib • Ivan Marcelo Gomes

Destaca-se, "mesmo sem qualquer intenção de contrariar a busca da autonomia e do empoderamento, ser possível que práticas que não se conformam com tal orientação possam constantemente atravessar os manejos e os equipamentos de saúde" (DALTIO, 2018, p. 95). Apesar disso, é preciso arriscar-se, deixar de se autorregular por achar que determinada ação não daria certo, e apostar no imprevisto. Segue um relato registrado no Diário de Campo a respeito de uma atividade de "Caminhada/Passeio":

Combinamos que iríamos fazer alguma brincadeira; então, quando fui até eles para dar uma proposta, o Amerildo e o Leonardo estavam num canto e vieram perguntando se poderiam fazer capoeira; disse que se o grupo concordasse, poderíamos. O grupo acolheu e fizemos uma roda espontaneamente, aonde cada um chegava e fazia de acordo com o que sabia ou achava melhor, dançando, fazendo alguns golpes. Paramos um pouco e continuamos com várias músicas de capoeira, cantando e batendo palma, até que, quando perguntei qual seria a próxima música, um usuário, que não lembro qual, começou a cantar músicas do grupo "é o tchan", e então cantamos, batemos palmas e dançamos. Já estava dando o horário para o retorno e eles pediram pra ficar mais, já que lá, como eles falaram, é mais legal de ficar do que no Caps. (Diário de Campo, 18 ago. 2016).

Durante as atividades da educação física no Caps foram priorizados encontros e momentos que permitissem aos próprios usuários planejar e construir a atividade. Aos poucos, professora e usuários do Caps foram conhecendo outras ruas do bairro e começaram a propor atividades lúdicas e de alongamento durante o percurso. Após algum tempo, os usuários puderam compor um cardápio de roteiros; a cada dia pactuava-se, antes de saírem para a caminhada, para onde o grupo iria e quais atividades seriam realizadas. Alguns trechos extraídos dos diários de campo ilustram tais momentos: 
Possibilidades e tensões no trabalho com as práticas corporais no cuidado em saúde... Gabriela Linhares Daltio • Leonardo Trápaga Abib • Ivan Marcelo Gomes

Hoje é dia de caminhada e logo que os usuários entram no Caps e me veem já perguntam: 'para onde vamos hoje?'. A resposta, como sempre, é que vamos decidir juntos no nosso ponto de partida, a calçada em frente ao Caps. (Diário de Campo, 20 abr. 2017).

No momento em que voltei do ginásio, era o momento em que deveria estar acontecendo outra oficina, a 'Oficina de Letras', que é oferecida pela psicóloga. A demanda pelo serviço era muito grande nesse dia e todos os funcionários estavam realizando alguma outra atividade e, portanto, solicitaram que a professora de Educação Física fizesse algo para passar ocupar o tempo. Fui explicar à gerente do serviço a conversa que fiz com os usuários sobre as atividades da sexta, e que, na ocasião, eles haviam demandado as oficinas da rotina (vôlei, letras e música), e não a troca aleatória por outra qualquer. (Diário de Campo, 24 jun. 2016).

A respeito do assunto, decidiu-se que esse deveria ser debatido em reunião da equipe. Por consenso, apoiou-se a ideia de priorizar as ações construídas com os usuários do serviço, respeitando seus desejos, anseios e demandas. Apesar de não ter sido fácil e ter havido momento de forte tensão, a discussão aconteceu, e tem que ser encarada como parte do processo de trabalho, o que, por si só, já seria vantajoso independentemente do mérito. Acreditamos que mesmo uma equipe convicta dos conceitos da reforma psiquiátrica, diante de uma situação polêmica, possa ter divergências, principalmente em aplicações práticas no cotidiano do serviço (DALTIO, 2018). Isso demonstra que as mudanças apregoadas pelo movimento da luta antimanicomial estão vivas no cotidiano do serviço, o que pode acontecer das mais diversas maneiras.

Entendemos que, ao propor o trabalho com conceitos como os de autonomia e empoderamento, pilares das políticas de saúde mental, faz-se necessário aproveitar toda e qualquer oportunida- 
Possibilidades e tensões no trabalho com as práticas corporais no cuidado em saúde... Gabriela Linhares Daltio • Leonardo Trápaga Abib • Ivan Marcelo Gomes

de. Como afirma Mendonça (2005, p. 628), “[...] além do tratamento clínico indispensável, o sujeito psicótico necessita ter reconstituído seu direito de criar, opinar, escolher, relacionar-se".

A Lei da Reforma Psiquiátrica destaca, em seu parágrafo único, ser direito desse individuo "[...] ter acesso ao melhor tratamento do sistema de saúde, consentâneo às suas necessidades" (BRASIL, 2001). Dentre elas, a busca por autonomia e empoderamento, que o auxiliarão em sua reinserção social. Diante desse objetivo para os sujeitos com transtorno mental grave, a prática da educação física no Caps II Mestre Álvaro foi "atravessada pelo investimento em atividades de circulação e interação com a comunidade do território adjacente, bem como com outras instituições - a partir de seus desejos, arranjos sociais, reconhecimento de suas limitações" (DALTIO, 2018, p. 97), objetivando ainda, acima de tudo, trabalhar habilidades presentes no indivíduo e as que pudessem despertar suas potencialidades. Para Emerich et al. $(2014,688)$, "[...] é necessário considerar o usuário dos serviços de saúde mental como protagonista e cogestor de sua vida, o que altera o modo de pensar a doença mental".

De acordo com Dutra et al. (2017), tecnologias de cuidado, como acolhimento, vínculo, corresponsabilização e autonomia desenvolvem-se a partir do afeto e do investimento no sujeito. Esses fatos podem nos dizer um pouco sobre como as tecnologias de cuidado afetam os usuários e quanto podem ajudar em todo contexto.

Destacamos, com essas observações, que a partir das propostas da educação física, algumas questões foram lançadas para discussão, o que demandou da profissional presente no Caps mobilizar diferentes conhecimentos e saberes, para além dos temas específicos da sua área de formação. Além disso, para desempenhar suas atividades, foram necessárias a construção e a reinvenção de uma educação física do Caps, sendo necessário acionar atividades para além daquelas voltadas para as atividades físicas e práticas corporais. Também fora preciso ajudar a manejar as situações que emergiam no interior do serviço para que se pudes- 
Possibilidades e tensões no trabalho com as práticas corporais no cuidado em saúde... Gabriela Linhares Daltio • Leonardo Trápaga Abib • Ivan Marcelo Gomes

se aproveitar ou trabalhar melhor os elementos necessários ao cuidado dos usuários do Caps a partir do referencial da reforma psiquiátrica. Enfim, criar momentos para possibilitar experiências que antes não faziam parte da vida desses sujeitos, potencializando, assim, movimentos de produção de vida.

\section{Considerações finais}

Podemos ponderar então que a educação física caminha na direção do que é possível fazer em saúde mental a partir do encontro com a comunidade para trabalhar o cuidado dos sujeitos que frequentam os serviços da rede de atenção psicossocial. Esse olhar também se modifica ao se discutir sobre o potencial das práticas corporais, quando realizadas em outro espaço de convívio e vínculo, para poderem contribuir na maior adesão ao tratamento. A partir das inquietações da professora do Caps em relação aos modos de trabalhar com a educação física na saúde mental, é que fora possível a reflexão e a transformação de sua própria prática. De forma concomitante a esse processo, também foram importantes as considerações oriundas das discussões com a equipe do Caps e os encontros e diálogos com os usuários do serviço, compondo, assim, um rol de momentos que contribuíram para a sua formação no campo da saúde mental.

Ao longo do texto, problematizamos a desinstitucionalização como o ponto fundamental para se pensar o exercício de ser profissional nessa área. Para tanto, almejar a desinstitucionalização perpassa também a transformação da sociedade e do próprio usuário. Esse processo deve estar presente na lida particular e única em cada encontro, na atuação profissional, na atuação como cidadão (DALTIO, 2018).

De maneira geral, os documentos que ajudam a orientar e organizar os serviços de saúde mental no Brasil, apresentados ao longo do texto, destacam conceitos importantes, como os de em- 
Possibilidades e tensões no trabalho com as práticas corporais no cuidado em saúde... Gabriela Linhares Daltio • Leonardo Trápaga Abib • Ivan Marcelo Gomes

poderamento e autonomia. Tais conceitos foram apresentados e discutidos ao analisar a relação entre o que está determinando nesses documentos e a realidade vivenciada no Caps II Mestre Álvaro. Destacamos algumas variáveis que foram importantes para tentar oportunizar atividades para tal fim. Há outras também, entretanto, que se poderiam considerar percalços, mas que tiveram a vantagem de estimular a perseverança. Se a luta ainda existe é porque há percalços ainda não superados. No caso específico, dependem de como a sociedade continua enxergando a "loucura", além de como ela é vista pelos profissionais envolvidos.

Diante dessa diversidade de acontecimentos de toda ordem para o desenvolvimento das atividades, os conceitos empoderamento e autonomia, em si polissêmicos, mostraram-se necessários (DALTIO, 2018). Também pudemos verificar que sua efetivação no mundo do trabalho e no espaço de vida/tratamento desses indivíduos aconteceu e ainda pode acontecer em meio a tensões, disputas, contradições.

Em um processo inacabado, a luta antimanicomial ainda vive, e é latente. Como percalço para a tentativa de oportunizar atividades congruentes com a reforma psiquiátrica, há ainda que citar a visão da sociedade sobre a loucura. Voltamos a enfatizar, no caso específico da população a que se destinam os Caps, que para se pensar em um modelo de cuidado em saúde mental é necessário prestar atenção à comunidade e ao próprio serviço e a como essa relação pode acontecer.

\title{
Referências
}

\begin{abstract}
ALMEIDA, K. et al. Empoderamento e atenção psicossocial: notas sobre uma associação de saúde mental. Interface -
\end{abstract} Comunicação, Saúde e Educação, Botucatu, v. 14, n. 34, p. 57789, jul./set. 2010. 
Possibilidades e tensões no trabalho com as práticas corporais no cuidado em saúde... Gabriela Linhares Daltio • Leonardo Trápaga Abib • Ivan Marcelo Gomes

ALVES, T. C. et al. A visão de usuários, familiares e profissionais acerca do empoderamento em saúde mental. Physis Revista de Saúde Coletiva, Rio de Janeiro, v. 23, n. 1, p. 51-71, 2013.

ALVARENGA, A. R; DIMENSTEIN, M. A. Reforma psiquiátrica e a desinstitucionalização da loucura. Interface - Comunicação, Saúde e Educação, Botucatu, v. 10, n. 20, p. 299-316, jul./dez. 2006.

AMORIM, A. K. M. A; DIMENSTEIN, M. Desinstitucionalização em saúde mental e práticas de cuidado no contexto do serviço residencial terapêutico. Ciência \& Saúde Coletiva, Rio de Janeiro, v. 14, n. 1, p. 195-204, jan./fev. 2009.

BRASIL. Decreto-lei n 10.216, de 6 de abril de 2001. Dispõe sobre a proteção e os direitos das pessoas portadoras de transtornos mentais e redireciona o modelo assistencial em saúde mental. Diário Oficial [da] República Federativa do Brasil, Brasília, 9 de abr. 2001. Seção 1, p. 2.

BRASIL. Portaria $n^{\circ} 2.446$, de 11 de novembro de 2014. Redefine a Política Nacional de Promoção da Saúde (PNPS). Diário Oficial [da] República Federativa do Brasil, Brasília, 13 nov. 2014. Disponível em: http://sintse.tse.jus.br/documentos/2014/Nov/13/ portaria-no-2-446-de-11-de- novembro-de-2014. Acesso em: 10 maio 2017.

BRASIL. Portaria n 336, de 19 de fevereiro de 2002. Estabelece CAPS I, CAPS II, CAPS III, CAPS i II e CAPS ad II. Diário Oficial [da] República Federativa do Brasil, Brasília, 20 fev. 2002. Disponível em: http://www2.camara.leg.br/legin/marg/portar/2002/portaria-336-19-fevereiro- 2002-333439-publicacaooriginal-1-ms.html. Acesso em: 5 maio 2017.

CARVALHO, S. R. Os múltiplos sentidos da categoria "empowerment" no projeto de Promoção à Saúde. Cadernos de Saúde Pública, Rio de Janeiro, v. 20, n. 4, p. 1088-1095, jul./ago. 2004. DALTIO, G. L. As práticas corporais no cuidado em saúde mental em um CAPS II na cidade da Serra/ES. 2018. 114 f. Dissertação (Mestrado em Educação Física) - Universidade Federal do Espírito Santo, Vitória, 2018. 
Possibilidades e tensões no trabalho com as práticas corporais no cuidado em saúde... Gabriela Linhares Daltio • Leonardo Trápaga Abib • Ivan Marcelo Gomes

DAMICO, J. G. S.; BILIBIO, L. F. Experimentação e encontro intercessor: produzindo pistas para a Educação Física na Saúde Mental. In: BAGRICHEVSKY, M.; ESTEVÃO, A (org.). Saúde coletiva: dialogando sobre interfaces temáticas. Ilhéus: Editora da UESC, 2015, p. 53-90.

DE PAULA, A. A. P.; BARRETO, R. O. “Rio da Vida Coletivo": empoderamento, emancipação e práxis. Rev. Adm. Pública, Rio de Janeiro, v. 48, n. 1, p. 111-130, jan./fev. 2014.

DUTRA, V. F. D. et al. Mediar a autonomia: um cuidado essencial. Escola Anna Nery Revista de Enfermagem, Rio de Janeiro, v. 21, n. 3, e20160284, 2017.

EMERICH, B. F. et al. Direitos na loucura: o que dizem usuários e gestores dos Centros de Atenção Psicossocial (CAPS). Interface - Comunicação, Saúde e Educação, Botucatu, v. 18, n. 51, p. 685-696, 2014.

FERREIRA, L. A. S. O trabalho da educação física na composição de equipe de saúde mental especializada em álcool e outras drogas. 2013. 109 f. Dissertação (Mestrado em Ciências do Movimento Humano) - Universidade Federal do Rio Grande do Sul, Porto Alegre, 2013.

FERREIRA, T. P. S. et al. Produção do cuidado em Saúde Mental: desafios para além dos muros institucionais. Interface Comunicação, Saúde e Educação, Botucatu, v. 21, n. 61, p. 373-384, jun. 2017.

FURTADO, P. R. et al. O trabalho do professor de educação física no Caps: aproximações iniciais. Movimento, Porto Alegre, v. 21, n. 1, p. 41-52, jan./mar. 2015.

GARCIA, C. A. S. et al. Micropolítica em saúde mental: um processo histórico em uma instituição de saúde. Psicologia \& Sociedade, Belo Horizonte, v. 23, n. esp., p. 161-169, 2011. GUEDES, A. C. et al. A mudança nas práticas em saúde mental e a desinstitucionalização: uma revisão integrativa. Rev. Eletr. Enf, Goiânia, v. 12, n. 3, p. 547-53. 2010. Disponível em: http://www. 
Possibilidades e tensões no trabalho com as práticas corporais no cuidado em saúde... Gabriela Linhares Daltio • Leonardo Trápaga Abib • Ivan Marcelo Gomes

fen.ufg.br/revista/v12/n3/v12n3a19.htm. Acesso em: 10 mar. 2017.

HIRDES, A. Autonomia e cidadania na reabilitação psicossocial: uma reflexão. Ciência \& Saúde Coletiva, Rio de Janeiro, v. 14, n. 1, p. 165-171, fev. 2009.

JORGE, M. S. B. et al. Promoção da Saúde Mental - Tecnologias do Cuidado: vínculo, acolhimento, co-responsabilização e autonomia. Ciência \& Saúde Coletiva, Rio de Janeiro, v. 16, n. 7, p. 3051-3060, jul. 2011.

LEONÍDIO, A. C. R. et al. O profissional de Educação Física no Centro de Atenção Psicossocial: percepção dos limites e potencialidades no processo de trabalho. Pesquisas e Práticas Psicossociais, São João del-Rei, v. 8, n. 2, p. 157-165, jul./dez. 2014.

KLEBA, M. E; WENDAUSEN, A. Empoderamento: processo de fortalecimento dos sujeitos nos espaços de participação social e democratização política. Saúde e Sociedade, São Paulo, v. 18, n. 4, p. 733-743, 2009.

MACHADO, D. Movimentos na Educação Física: por uma ética dos corpos. 2011. 113 f. Dissertação (Mestrado em Educação) Universidade Federal do Rio Grande do Sul, Porto Alegre, 2011.

MENDONÇA, T. C. P. As Oficinas na Saúde Mental: Relato de uma Experiência na Internação. Psicologia Ciência e Profissão, Brasília, v. 25, n. 4, p. 626-635, 2005.

MIRANDA, F. A. N; AZEVEDO, D. M. Oficinas terapêuticas como instrumento de reabilitação psicossocial: percepção de familiares. Escola Anna Nery Revista de Enfermagem, Rio de Janeiro, v. 15, n. 2, p. 339- 345, abr./jun. 2011.

PASSOS, E.; BARROS, R. B. A cartografia como método de pesquisa-intervenção. In: PASSOS. E.; KASTRUP, V. E. L. (org.). Pistas do método da cartografia: Pesquisa-intervenção e produção de subjetividade. Porto Alegre: Sulina, 2012, p.131-149. 
Possibilidades e tensões no trabalho com as práticas corporais no cuidado em saúde... Gabriela Linhares Daltio • Leonardo Trápaga Abib • Ivan Marcelo Gomes

SANTOS, S. F. S. et al. Experiências da Educação Física na formação e na atuação no Sistema Único de Saúde. In: BENEDETTI, T. R. B. et al. (org.). A formação do profissional de Educação Física para o setor saúde. Florianópolis: Postmix, 2014, p. 128-159 SOARES, C. L. et al. Metodologia do Ensino da Educação Física. São Paulo: Cortez, 1992.

WACHS, F. Educação física e saúde mental: uma prática de cuidado emergente em centros de atenção psicossocial. 2008. 145f. Dissertação (Mestrado em Ciências do Movimento Humano) - Universidade Federal do Rio Grande do Sul, Porto Alegre, 2008. WACHS, F. Educação Física e Saúde Mental: algumas problemáticas recorrentes no cenário de práticas. In: WACHS, F.; ALMEIDA, U. R.; BRANDÃO, F. (org.). Educação Física e Saúde Coletiva Cenários, experiências e artefatos culturais. Porto Alegre: Rede Unida, 2016, p. 47-62.

\section{Financiamento}

Esse trabalho faz parte do projeto "A educação do corpo e em saúde nos projetos, práticas e narrativas identitárias na região metropolitana de Vitória" financiado pela Fundação de Amparo à Pesquisa e Inovação do Espírito Santo (EDITAL FAPES Nº4/2015)

\section{Aprovação de comitê de ética em pesquisa}

Pesquisa aprovada pelo Comitê de Ética da Universidade Federal do Espírito Santo. Título: Implicação das práticas corporais no cuidado em saúde mental em um CAPS II da Serra/ES 
Possibilidades e tensões no trabalho com as práticas corporais no cuidado em saúde... Gabriela Linhares Daltio • Leonardo Trápaga Abib • Ivan Marcelo Gomes

\section{Publisher}

Universidade Federal de Goiás. Faculdade de Educação Física e Dança. Publicação no Portal de Periódicos UFG. As ideias expressadas neste artigo são de responsabilidade de seus autores, não representando, necessariamente, a opinião dos editores ou da universidade. 